\title{
Presynaptic Mitochondrial Calcium Sequestration Influences Transmission at Mammalian Central Synapses
}

\author{
Brian Billups and lan D. Forsythe \\ Department of Cell Physiology and Pharmacology, University of Leicester, Leicester LE1 9HN, United Kingdom
}

Beyond their role in generating ATP, mitochondria have a high capacity to sequester calcium. The interdependence of these functions and limited access to presynaptic compartments makes it difficult to assess the role of sequestration in synaptic transmission. We addressed this important question using the calyx of Held as a model glutamatergic synapse by combining patch-clamp with a novel mitochondrial imaging method. Presynaptic calcium current, mitochondrial calcium concentration $\left(\left[\mathrm{Ca}^{2+}\right]_{\text {mito }}\right.$, measured using rhod-2 or rhod-FF), cytoplasmic calcium concentration ( $\left[\mathrm{Ca}^{2+}\right]_{\text {cyto }}$, measured using fura-FF), and the postsynaptic current were monitored during synaptic transmission. Presynaptic $\left[\mathrm{Ca}^{2+}\right]_{\text {cyto }}$ rose to $8.5 \pm 1.1 \mu \mathrm{M}$ and decayed rapidly with a time constant of $45 \pm 3 \mathrm{msec}$; presynaptic $\left[\mathrm{Ca}^{2+}\right]_{\text {mito }}$ also rose rapidly to $>5 \mu \mathrm{m}$ but decayed slowly with a half-time of $1.5 \pm 0.4 \mathrm{sec}$. Mitochondrial depolarization with rotenone and carbonyl cyanide $p$-trifluoromethoxyphenylhydrazone abolished mitochondrial calcium rises and slowed the removal of $\left[\mathrm{Ca}^{2+}\right]_{\text {cyto }}$ by $239 \pm 22 \%$. Using simultaneous

Neurotransmitter release is triggered by $\mathrm{Ca}^{2+}$ influx through voltage-gated channels (Katz, 1969). Factors regulating the spatiotemporal profile of the presynaptic cytoplasmic calcium transient influence release probability, vesicle recycling, and information processing in the brain. Mitochondria are capable of having an important effect on these processes because they can sequester large quantities of calcium (Duchen, 1999; Nicholls and Budd, 2000), are present at high concentrations in presynaptic terminals, and can be tethered to vesicle release sites (Rowland et al., 2000). Presynaptic buffering of calcium by mitochondria occurs at the mouse (David and Barrett, 2000), lizard (David et al., 1998; David, 1999), and crustacean (Tang and Zucker, 1997) neuromuscular junctions, but is inconsistently observed at the goldfish retinal bipolar cell terminal (Kobayashi and Tachibana, 1995; Zenisek and Matthews, 2000). At the crustacean neuromuscular junction, mitochondrial calcium sequestration over 7-10 min of tetanic stimulation, and its subsequent release, causes post-tetanic potentiation (PTP) (Tang and Zucker, 1997). Although mitochondria are known to buffer calcium and influence secretion of

Received Feb. 20, 2002; revised April 25, 2002; accepted April 29, 2002.

This work was supported by the Wellcome Trust. Thanks to Dr. Euan Brown for assistance in some of the preliminary experiments and to Prof. Michael Duchen for advice on mitochondrial pharmacology and imaging. Thanks also to the Leicester University mechanical and electrical workshops for technical assistance and to Dr. Margaret Barnes-Davies, Dr. David DiGregorio, Dr. Angus Silver, Prof. Nick Standen, and Dr. Martine Hamann for helpful comments on this manuscript.

Correspondence should be addressed to Ian Forsythe, Department of Cell Physiology and Pharmacology, University of Leicester, P.O. Box 138, Leicester LE1 9HN, UK. E-mail: idf@le.ac.uk.

Copyright (C) 2002 Society for Neuroscience $\quad 0270-6474 / 02 / 225840-08 \$ 15.00 / 0$ presynaptic and postsynaptic patch clamp, combined with presynaptic mitochondrial and cytoplasmic imaging, we investigated the influence of mitochondrial calcium sequestration on transmitter release. Depletion of ATP to maintain mitochondrial membrane potential was blocked with oligomycin, and ATP was provided in the patch pipette. Mitochondrial depolarization raised $\left[\mathrm{Ca}^{2+}\right]_{\text {cyto }}$ and reduced transmitter release after short EPSC trains $(100 \mathrm{msec}, 200 \mathrm{~Hz}$ ); this effect was reversed by raising mobile calcium buffering with EGTA. Our results suggest a new role for presynaptic mitochondria in maintaining transmission by accelerating recovery from synaptic depression after periods of moderate activity. Without detectable thapsigargin-sensitive presynaptic calcium stores, we conclude that mitochondria are the major organelle regulating presynaptic calcium at central glutamatergic terminals.

Key words: mitochondria; calcium imaging; calyx of Held; short-term plasticity; rhod-2; rhod-FF; fura-FF

peptides from sympathetic ganglia (Peng, 1998; Cao and Peng, 1999), pituitary gonadotropes (Kaftan et al., 2000), and chromaffin cells (Herrington et al., 1996; Park et al., 1996; Xu et al., 1997; Giovannucci et al., 1999; Sorimachi et al., 1999; Montero et al., 2000), relatively little is known about the role mitochondria play in influencing neurotransmission in the brain because conventional mitochondrial calcium imaging techniques are difficult to apply in situ. Additional complications arise because mitochondrial depolarization blocks both calcium accumulation and ATP synthesis, leading to indirect effects on synaptic transmission attributable to ATP depletion.

We developed a technique to image mitochondrial calcium concentrations $\left(\left[\mathrm{Ca}^{2+}\right]_{\text {mito }}\right)$ in single cells and synaptic terminals by including the AM form of a rhod-based dye (rhod-2 or rhodFF) in the patch pipette. These dyes are cationic (Minta et al., 1989) and are preferentially accumulated into the mitochondria when AM is loaded into cells. However, after AM loading of intact cells with rhod dyes, a substantial cytoplasmic component is still observed (typically 30\%) (Kaftan et al., 2000), which must be reduced by up to $24 \mathrm{hr}$ of washing (Simpson and Russell, 1996, 1998), permeabilizing cells with digitonin (Rohacs et al., 1997; Szabadkai et al., 2001), or manganese quenching (Mironov and Richter, 2001). By including the AM dye in the patch pipette we can avoid problems of cytoplasmic loading because cytoplasmic rhod fluorescence is removed by dialysis (back into the patch pipette), leaving fluorescence solely from the mitochondrial compartment. Extensive periods of washing or quenching of cytoplasmic fluorescence were not required, and measurement of cytoplasmic calcium concentrations $\left(\left[\mathrm{Ca}^{2+}\right]_{\text {cyto }}\right)$ in the same terminal 
was possible by also including fura-FF potassium salt in the patch pipette.

In this study, we examined the role of mitochondria in a mammalian glutamatergic synapse known as the calyx of Held (Forsythe, 1994; Borst et al., 1995; von Gersdorff et al., 1997). Using simultaneous electrophysiological recording combined with intracellular calcium imaging of both $\left[\mathrm{Ca}^{2+}\right]_{\text {cyto }}$ and $\left[\mathrm{Ca}^{2+}\right]_{\text {mito }}$, we examined the influence of mitochondria on neurotransmitter release on millisecond time scales.

\section{MATERIALS AND METHODS}

Electrophysiology. Transverse brainstem slices $(\sim 150-\mu \mathrm{m}$-thick) were prepared from 10- to 12-d-old Lister Hooded rats, killed by decapitation. Slices were incubated for $1 \mathrm{hr}$ at $37^{\circ} \mathrm{C}$ in artificial CSF (aCSF), and then stored for up to $8 \mathrm{hr}$ at room temperature before transferring to the experimental chamber for recording at $37^{\circ} \mathrm{C}$. Medial nucleus of the trapezoid body (MNTB) neurons and calyces of Held were visualized with infrared differential interference contrast (DIC) optics on a Nikon E600FN microscope with a $60 \times$, numerical aperture 1.0, waterimmersion, fluor lens. The aCSF contained (in $\mathrm{mM}$ ): $125 \mathrm{NaCl}, 2.5 \mathrm{KCl}$, 10 glucose, $1.25 \mathrm{NaH}_{2} \mathrm{PO}_{4}, 26 \mathrm{NaHCO}_{3}, 1 \mathrm{MgCl}_{2}, 2 \mathrm{CaCl}_{2}, 3$ myoinositol, 0.5 ascorbic acid, 2 Na-pyruvate, 10 TEA-Cl, and 0.001 TTX, $\mathrm{pH}$ 7.4, when gassed with $95 \% \mathrm{O}_{2}$ and $5 \% \mathrm{CO}_{2}$. Whole-cell patch-clamp recordings were made from both the synaptic terminal and postsynaptic cell using thick-walled glass pipettes (GC150F-7.5; Clark Electromedical, Reading, UK) with Axopatch 200B amplifiers (Axon Instruments, Foster City, CA), filtered at $5 \mathrm{kHz}$ (8-pole Bessel filter) and sampled at $10 \mathrm{kHz}$. Currents were recorded with pClamp software (Axon Instruments). Whole-cell access resistances were $<10 \mathrm{M} \Omega$ for the postsynaptic cell and $<30 \mathrm{M} \Omega$ for the presynaptic terminal, and were compensated $>70 \%$ with a $10 \mu \mathrm{sec}$ lag time. The intracellular solution for the postsynaptic cell contained (in mM): $110 \mathrm{CsCl}, 40$ HEPES, 10 TEA-Cl, $12 \mathrm{Na}_{2}-$ phosphocreatine, and 1 EGTA, $\mathrm{pH}$ adjusted to 7.3 with $\mathrm{CsOH}$. The intracellular solution for the presynaptic terminal contained (in $\mathrm{mM}$ ): 110 $\mathrm{CsCl}, 40 \mathrm{HEPES}, 10 \mathrm{TEA}-\mathrm{Cl}, 12 \mathrm{Na}_{2}$-phosphocreatine, 0.2 EGTA, 10 Na-glutamate, $2 \mathrm{Mg}$-ATP, and $0.5 \mathrm{Na}-\mathrm{GTP}$, pH adjusted to 7.3 with $\mathrm{CsOH}$. A free calcium concentration of $100 \mathrm{~nm}$ (measured with fura-2) was attained by the addition of $8 \mu \mathrm{M} \mathrm{CaCl}_{2}$. A liquid junction potential of $3.4 \mathrm{mV}$ was not corrected for. During paired presynaptic and postsynaptic recordings postsynaptic AMPA receptor responses were pharmacologically isolated, and desensitization and saturation minimized by the addition of $50 \mu \mathrm{M}$ cyclothiazide and $3 \mathrm{~mm}$ kynurenate to the external medium. NMDA receptors were blocked with $50 \mu \mathrm{M}$ DL-2-amino-5phosphonopentanoic acid and $10 \mu \mathrm{M}(+)$-MK 801 maleate.

Calcium imaging. Calcium-sensitive fluorescent dyes $(200 \mu \mathrm{M}$ fura-FF potassium salt and $10 \mu \mathrm{M}$ of either rhod-2 AM or rhod-FF AM) were simultaneously added to the presynaptic intracellular solution to visualize the calcium transients in the cytosol and mitochondria of the terminal. After establishment of whole-cell recording, $\sim 10 \mathrm{~min}$ was required for rhod fluorescence to be detected in the mitochondria. Dyes were excited at 380 and $550 \mathrm{~nm}$, respectively, with a Polychrome II monochromator (T.I.L.L. Photonics, Martinsried, Germany). Emitted light was separated by 400 or $575 \mathrm{~nm}$ dichroic mirrors and filtered with either a 420 or a $590 \mathrm{~nm}$ long-pass emission filter. Fluorescence images were acquired every $10 \mathrm{msec}$ with a PentaMAX cooled CCD camera via a Gen IV image intensifier (Princeton Instruments, Trenton, NJ) and analyzed with MetaFluor software (Universal Imaging, West Chester, PA). Imaging of $\left[\mathrm{Ca}^{2+}\right]_{\text {cyto }}$ and $\left[\mathrm{Ca}^{2+}\right]_{\text {mito }}$ in the same cell was achieved by stimulating once while imaging at $380 \mathrm{~nm}$, followed by once at $550 \mathrm{~nm}$, repeating this alternate excitation and averaging the relevant signals. An interval between each stimulus of $2 \mathrm{~min}$ was required to allow reestablishment of baseline calcium levels; hence long duration stable recordings were required for data acquisition. Presynaptic calcium transients were imaged with fura-FF using only $380 \mathrm{~nm}$ excitation to enhance the rate of data acquisition and also because kynurenic acid absorbs much of the excitation light below $360 \mathrm{~nm}$. The fluorescence was converted to $\left[\mathrm{Ca}^{2+}\right]_{\mathrm{i}}$ using the following equation (Jaffe et al., 1992; Helmchen et al., 1997):

$$
\left[\mathrm{Ca}^{2+}\right]_{\mathrm{i}}=\frac{\left[\mathrm{Ca}^{2+}\right]_{\mathrm{rest}}+K_{\mathrm{d}}(\Delta F / F) /(\Delta F / F)_{\max }}{\left(1-(\Delta F / F) /(\Delta F / F)_{\max }\right)}
$$

A value of $-0.76 \pm 0.03$ was established for $(\Delta F / F)_{\max }$ at the end of 20 experiments by repeated electrical zapping of the terminal $(-1.3 \mathrm{~V}$
A

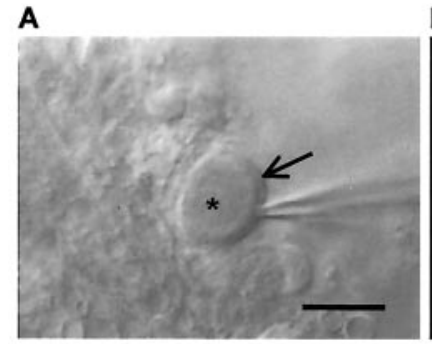

B

C
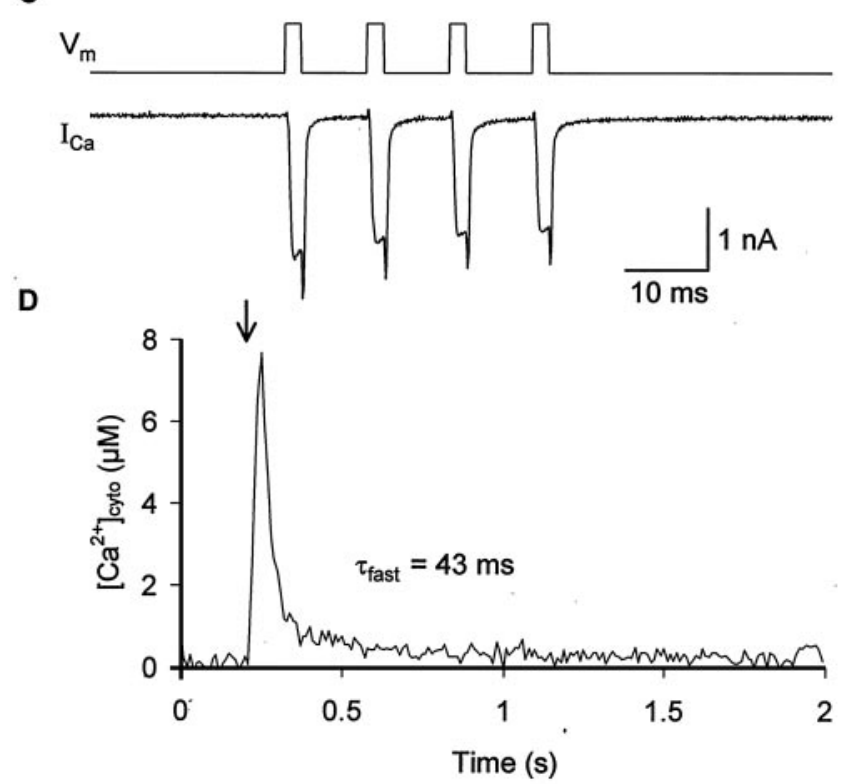

Figure 1. Rapid time course of presynaptic $\left[\mathrm{Ca}^{2+}\right]$ transients in the calyx of Held. $A$, DIC image of a calyx of Held (arrow) surrounding a postsynaptic MNTB neuron (asterisk). Scale bar, $15 \mu \mathrm{m}$. Patch pipette is to the right. $B$, Fluorescence image from the same calyx filled with fura-FF via diffusion from the patch pipette. $C$, Calcium currents (bottom trace) recorded in the calyx of Held in response to four voltage steps $(-80$ to 0 $\mathrm{mV}$ depolarization, $2 \mathrm{msec}$ duration at $100 \mathrm{~Hz}$; top trace). $D$, $\left[\mathrm{Ca}^{2+}\right]_{\text {cyto }}$ time course during stimulation recorded simultaneously with the calcium current from the same terminal as in $C$ using fura-FF imaging at a frame frequency of $100 \mathrm{~Hz}$ (stimulation at arrow as shown in $C$ ).

pulses for $5 \mathrm{msec}$ ) to cause a saturating $\left[\mathrm{Ca}^{2+}\right]_{\text {cyto }}$ rise. A $K_{\mathrm{d}}$ of $10 \mu \mathrm{M}$ was used, as previously determined for fura-FF in this preparation (Bollmann et al., 2000; Schneggenburger and Neher, 2000).

Fluorescent dyes were obtained from Molecular Probes (Eugene, OR), glutamate receptor antagonists from Tocris Cookson (Bristol, UK), TTX from Latoxan (Valence, France), and thapsigargin and Ru360 from Calbiochem (Nottingham, UK). All other chemicals were obtained from Sigma (Poole, UK). Ru360 was diluted from a $1 \mathrm{~mm}$ stock made daily in deoxygenated $1 \mathrm{~mm}$ Na-ascorbate. Frozen Ru360 stock solution lost activity overnight. Data are expressed as the mean \pm SEM. Statistical significance $(p<0.05)$ was tested with paired or unpaired two-tailed $t$ test as appropriate. All experiments were performed at physiological temperature $\left(35-37^{\circ} \mathrm{C}\right)$.

\section{RESULTS}

Calcium influx into the calyx of Held (Fig. $1 A$ ) was triggered by $2 \mathrm{msec}$ step depolarizations under voltage-clamp conditions in the presence of sodium and potassium channel blockers (Helmchen et al., 1997; Borst and Sakmann, 1998). To maintain the balance between physiological calcium homeostatic mechanisms, experiments were conducted at a temperature of $35-37^{\circ} \mathrm{C}$, and intracellular mobile calcium buffering was maintained with $200 \mu \mathrm{M}$ EGTA (Borst and Sakmann, 1996). Inclusion in the patch pipette 
of the low-affinity calcium indicator fura-FF (Fig. 1B) allowed quantitative imaging of $\left[\mathrm{Ca}^{2+}\right]_{\text {cyto }}$ (Helmchen et al., 1997; Bollmann et al., 2000; Schneggenburger and Neher, 2000) simultaneously with measurement of the presynaptic calcium current generated by P-type calcium channels (Forsythe et al., 1998; Iwasaki and Takahashi, 1998) (Fig. 1C). Presentation of four stimuli at $100 \mathrm{~Hz}$ caused a rapid rise of presynaptic $\left[\mathrm{Ca}^{2+}\right]_{\text {cyto }}$ to $8.5 \pm 1.1 \mu \mathrm{M}(n=5)$ (Fig. $1 D)$ and decayed in a double exponential with time constants $(\tau)$ of $43 \pm 2$ and $311 \pm 59 \mathrm{msec}\left(\tau_{\text {fast }}\right.$ was $83 \pm 2 \%$ peak amplitude).

Mitochondrial calcium sequestration was first examined by imaging the fluorescent calcium indicator rhod-2 (Minta et al., 1989), which preferentially accumulates in mitochondria. The AM form of rhod-2 is cationic and membrane-permeant but possesses no detectable calcium-dependent fluorescence. When added via the patch solution, it accumulated in mitochondria because of the large transmembrane potential $\left(\Delta \psi_{\mathrm{m}}\right)$ and was activated by mitochondrial esterases. Once de-esterified, rhod-2 is retained in the mitochondrial matrix, regardless of $\Delta \psi_{\mathrm{m}}$. Rhod-2 fluorescence was absent from the cytoplasm and axon (Fig. 2C) because of dialysis of cytoplasmic de-esterified rhod-2 (and possibly the esterases themselves) into the patch pipette. The different fluorescent absorbance spectra of rhod-2 and fura-FF permitted measurement of both $\left[\mathrm{Ca}^{2+}\right]_{\text {cyto }}$ and $\left[\mathrm{Ca}^{2+}\right]_{\text {mito }}$ in the same presynaptic terminal. Depolarization-evoked calcium entry into the presynaptic terminal resulted in calcium accumulation in the mitochondria, as indicated by an increase in rhod-2 fluorescence (Fig. 2D).

Saturation of rhod-2 by calcium $\left(K_{\mathrm{d}}, 570 \mathrm{~nm}\right)$ severely limited the ability to resolve changes in $\left[\mathrm{Ca}^{2+}\right]_{\text {mito }}$. Repetition of the stimulus produced no additional increase in fluorescence signal $(n=4 ; p=0.27)$ (Fig. $2 D$, gray trace), suggesting that the rhod-2 was indeed saturated in these experiments. In contrast, repetitive stimulation of presynaptic terminals after mitochondrial loading with the lower affinity dye rhod-FF $\left(K_{\mathrm{d}}, 19 \mu \mathrm{M}\right)$, resulted in progressive summation and greater fluorescent responses to repetitive stimulation ( $n=4 ; p<0.01$ ) (Fig. 2E, gray trace). Because rhod-FF was not saturated under these conditions, the time course of $\left[\mathrm{Ca}^{2+}\right]_{\text {mito }}$ could be determined. The half risetime of $\left[\mathrm{Ca}^{2+}\right]_{\text {mito }}$ after four stimuli at $100 \mathrm{~Hz}$ was $47 \pm 3 \mathrm{msec}$, and the half decay time $1.5 \pm 0.4 \mathrm{sec}(n=3)$. Although fura-FF and rhod-FF have similar affinities for calcium, the rhod-FF signal was notably slower than the kinetics of $\left[\mathrm{Ca}^{2+}\right]_{\text {cyto }}$ recorded with fura-FF (Fig. 1D), consistent with the notion that these two dyes are signaling calcium changes in different subcellular compartments. The peak $\left[\mathrm{Ca}^{2+}\right]_{\text {mito }}$ could not be estimated from the rhod-FF data because we could not measure a calcium-saturated fluorescent signal from the mitochondria. However, the rhod-2 data (Fig. $2 D$ ) represents an increase in $\left[\mathrm{Ca}^{2+}\right]_{\text {mito }}$ of at least 5 $\mu \mathrm{M}$, taking into account its $K_{\mathrm{d}}$, saturation, and assuming a resting $\left[\mathrm{Ca}^{2+}\right]_{\text {mito }}$ of 100-200 nM (Babcock et al., 1997; Zhou et al., 1998). The effects of mitochondrial inhibitors on the fluorescence change were used to confirm the mitochondrial origin of the rhod fluorescence signal.

\section{Inhibition of mitochondrial calcium sequestration}

Accumulation of calcium by mitochondria was inhibited by three separate methods. First, agents were applied that disrupt $\Delta \psi_{\mathrm{m}}$ because mitochondrial calcium accumulation is driven by $\Delta \psi_{\mathrm{m}}$ (Gunter and Pfeiffer, 1990; Gunter and Gunter, 1994; Duchen, 1999; Nicholls and Budd, 2000). Calcium uptake into mitochondria was inhibited by $>93 \%(n=5 ; p<0.05)$ (Fig. $2 D)$ with
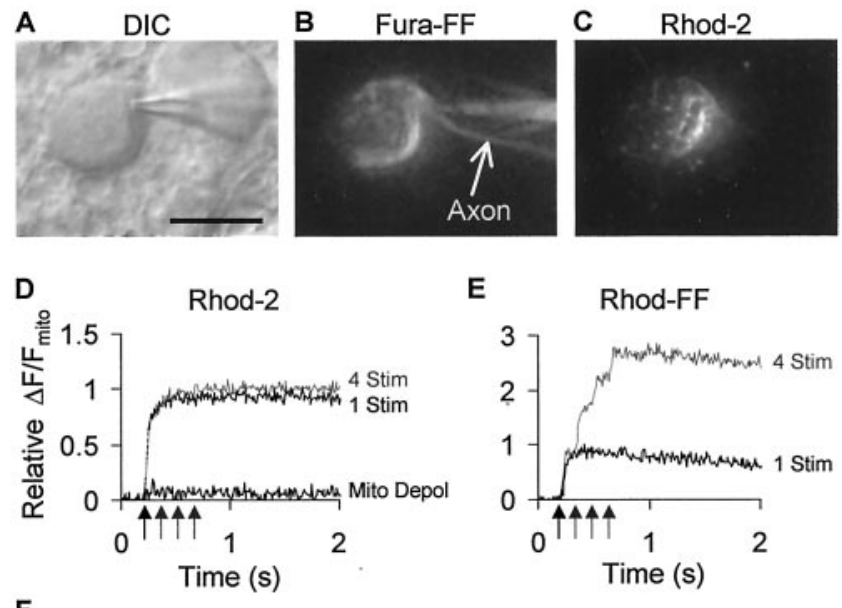

F

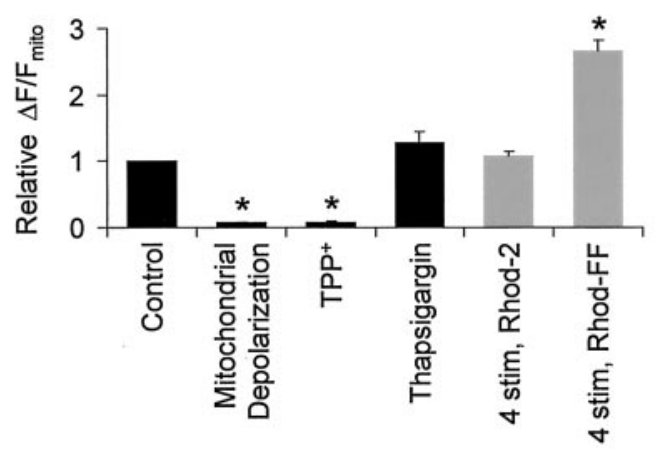

Figure 2. Slow time course of presynaptic mitochondrial $\left[\mathrm{Ca}^{2+}\right]$ transients. $A$, DIC image of the presynaptic terminal. Scale bar, $15 \mu \mathrm{m}$. $B$, Projected stack of fura-FF images focused through the entire terminal. $C$, Projected stack of rhod-2 images showing that fluorescence was concentrated in the terminal but was absent from the pipette and axon regions. $D,\left[\mathrm{Ca}^{2+}\right]_{\text {mito }}$ rose rapidly on stimulation (as in Fig. $1 C$, black trace) but decayed slowly. Four groups of four stimuli (the same protocol as in Fig. $1 C$ repeated 4 times $150 \mathrm{msec}$ apart, gray trace) had a similar time course and amplitude, indicating saturation of the dye. Mitochondrial depolarization (perfusion of $25 \mu \mathrm{M}$ rotenone and $1 \mu \mathrm{M}$ FCCP in the presence of $5 \mu \mathrm{g} / \mathrm{ml}$ oligomycin) completely blocked calcium accumulation by the mitochondria after one group of four stimuli (bottom black trace). E, Rhod-FF fluorescence signals were not saturated by four groups of four stimuli ( gray trace) compared with one group of stimuli (black trace). The traces in $D$ and $E$ are shown normalized to the change in fluorescence after one group of stimuli. $F$, Summary data show that mitochondrial calcium uptake was inhibited by mitochondrial depolarization and $10 \mu \mathrm{M}$ $\mathrm{TPP}^{+}$but not $1 \mu \mathrm{M}$ thapsigargin. Mitochondrial calcium sequestration saturated rhod-2 $\left(K_{\mathrm{d}}, 570 \mathrm{nM}\right)$ but not rhod-FF $\left(K_{\mathrm{d}}, 19 \mu \mathrm{M}\right)$. Asterisks indicate statistical significance $(p<0.05)$.

perfusion of rotenone (a blocker of complex I of the respiratory chain) combined with carbonyl cyanide $p$-trifluoromethoxyphenylhydrazone (FCCP) (a protonophore) and oligomycin (a blocker of $\mathrm{F}_{0} \mathrm{~F}_{1}$-ATPase, preventing use of ATP to maintain proton gradients). Second, tetraphenylphosphonium $\left(\mathrm{TPP}^{+}\right)$, which blocks mitochondrial calcium efflux without effecting ATP production (Aiuchi et al., 1985) (but see Nicholls and Budd, 2000) and mitochondrial calcium uptake (Tang and Zucker, 1997) also blocked the $\left[\mathrm{Ca}^{2+}\right]_{\text {mito }}$ rise after stimulation of the calyx of Held $(n=4 ; p<0.05)$ (Fig. $2 F)$. Third, the inclusion in the patch pipette of Ru360 (a specific inhibitor of the mitochondrial calcium uniporter) (Matlib et al., 1998) prevented the stimulus-induced rise in $\left[\mathrm{Ca}^{2+}\right]_{\text {mito }}(n=3 ; p<0.01)$ (Fig. $\left.3 F\right)$. By contrast, thapsigargin, which blocks calcium pumps into intracellular 
A
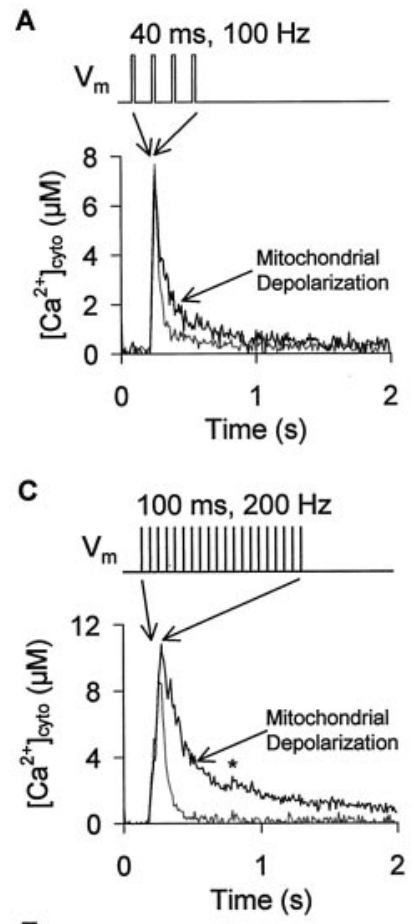

E

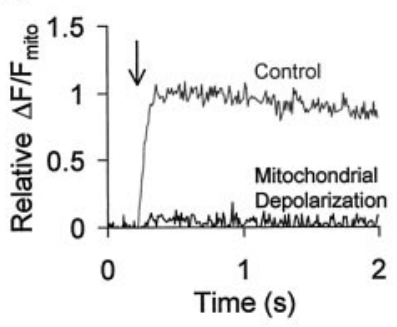

B

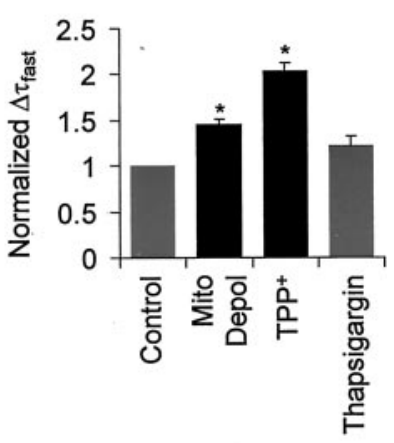

D

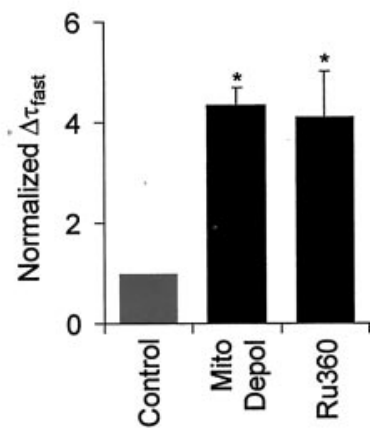

$\mathbf{F}$

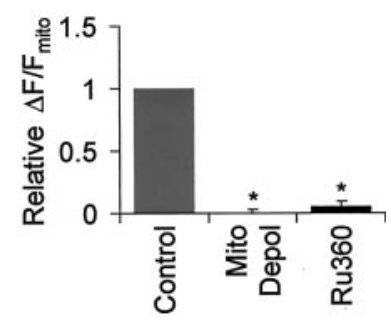

Figure 3. Mitochondrial calcium sequestration buffers $\left[\mathrm{Ca}^{2+}\right]_{\text {cyto }} . A$, The $\left[\mathrm{Ca}^{2+}\right]_{\text {cyto }}$ transient (using the same stimulation protocol as Fig. 1) was significantly slowed by mitochondrial depolarization, but the peak rise was not significantly altered ( $97 \pm 6 \%$ of control; $n=5 ; p=0.66)$. $B$, The $\tau_{\text {fast }}\left[\mathrm{Ca}^{2+}\right]_{\text {cyto }}$ decay was slowed by mitochondrial depolarization and $\mathrm{TPP}^{+}$but not by thapsigargin ( $129 \pm 9 \%$ of control; $\left.n=3 ; p=0.08\right)$. $C$, $D$, Trains of presynaptic depolarization ( -80 to $0 \mathrm{mV}, 1 \mathrm{msec}$ stimulation repeated 20 times at $200 \mathrm{~Hz}$ ) produced rises in $\left[\mathrm{Ca}^{2+}\right]_{\text {cyto }}$ that were also significantly slowed by mitochondrial depolarization or $1 \mu \mathrm{M}$ Ru360. E, $F$, $\left[\mathrm{Ca}^{2+}\right]_{\text {mito }}$ recorded with rhod-FF increased during stimulation (at arrow as in $C$ ). This increase was blocked by mitochondrial depolarization or Ru360. Asterisks indicate statistical significance $(p<0.05)$.

stores, did not prevent the rise of rhod-2 fluorescence $(n=3 ; p=$ $0.19)$ (Fig. 2F). The antagonist profile outlined in Figure 2 and the prolonged time course of the $\left[\mathrm{Ca}^{2+}\right]_{\text {mito }}$ rise clearly demonstrate that the rhod-AM dyes, loaded by this method, report $\Delta\left[\mathrm{Ca}^{2+}\right]$ from the mitochondrial compartment alone.

\section{Mitochondria rapidly buffer presynaptic calcium}

Dissipation of $\Delta \psi_{\mathrm{m}}$ by rotenone and FCCP in the presence of oligomycin significantly slowed the $\left[\mathrm{Ca}^{2+}\right]_{\text {cyto }}$ transient after stimulation of the presynaptic terminal (Fig. $3 A$ ). The $\tau_{\text {fast }}$ was slowed by $45 \pm 6 \%(n=5 ; p<0.01)$ (Fig. $3 B)$. This slowing was not attributable to ATP depletion from the terminal, because ATP was continually available by dialysis from the patch pipette, and application of oligomycin alone had no significant effect on $\tau_{\text {fast }}(110 \pm 7 \%$ of control; $n=3 ; p=0.30)$. This excludes the possibility that mitochondrial inhibition slows the $\left[\mathrm{Ca}^{2+}\right]_{\text {cyto }}$ transient by reducing cytoplasmic [ATP], which could inhibit the

plasma membrane calcium ATPase and, indirectly, $\mathrm{Na}^{+}-\mathrm{Ca}^{2+}$ exchange. In addition, $\mathrm{TPP}^{+}$and Ru360, which do not affect mitochondrial ATP production, had similar effects on $\tau_{\text {fast }}$, slowing it to $203 \pm 9 \%$ and $412 \pm 88 \%$, respectively (Fig. $3 B, D$, note the different stimulus protocols). Thapsigargin had no significant effect on $\left[\mathrm{Ca}^{2+}\right]_{\text {cyto }}(n=3 ; p=0.08)$ (Fig. $\left.3 B\right)$, consistent with a lack of substantial calcium sequestration into the endoplasmic reticulum. Longer, faster trains of stimuli (1 msec step depolarizations, repeated 20 times at $200 \mathrm{~Hz}$ ) were also used, which mimic the action potential firing patterns observed at this synapse (Brownell, 1975). As with the briefer stimuli, mitochondrial depolarization significantly slowed the decay of the $\left[\mathrm{Ca}^{2+}\right]_{\text {cyto }}$ transient (Fig. 3C,D), $\tau_{\text {fast }}$ being slowed to $436 \pm 32 \%$ (from $45 \pm 3$ to $239 \pm 22 \mathrm{msec} ; n=6 ; p<0.01)$. Concurrent $\left[\mathrm{Ca}^{2+}\right]_{\text {mito }}$ recordings with rhod-FF demonstrated that mitochondrial depolarization or inclusion of Ru360 inside the patch pipette prevented mitochondrial calcium sequestration during the longer trains of stimulation (Fig. $3 E, F$ ).

Mitochondrial depolarization had no effect on the magnitude of the presynaptic calcium current $\left(I_{\mathrm{Ca}}\right)$. A statistically insignificant time-dependent rundown of $I_{\mathrm{Ca}}$ was observed at physiological temperature $\left(I_{\mathrm{Ca}}\right.$ declined by $15 \pm 4 \%$ over $\sim 30 \mathrm{~min} ; n=5$; $p=0.06)$. $I_{\mathrm{Ca}}$ was stable in experiments performed at room temperature, whereas mitochondrial depolarization still slowed $\left[\mathrm{Ca}^{2+}\right]_{\text {cyto }}$ transients at these lower temperatures (data not shown $)$. TPP ${ }^{+}$, however, reduced $I_{\mathrm{Ca}}$ by $44 \pm 8 \%(n=3 ; p<$ $0.05)$, and the peak $\left[\mathrm{Ca}^{2+}\right]_{\text {cyto }}$ by $36 \pm 9 \%$, suggesting that $\mathrm{TPP}^{+}$ has additional nonspecific effects on presynaptic voltage-gated calcium channels.

\section{Presynaptic mitochondria influence neurotransmitter release}

To assess whether mitochondrial calcium buffering affects neurotransmitter release, simultaneous recordings were made from the presynaptic terminal and postsynaptic neuron (Fig. 4A) (Borst et al., 1995; Takahashi et al., 1996). This was done in the presence of cyclothiazide and kynurenic acid to minimize receptor desensitization and saturation (Neher and Sakaba, 2001). A conditioning train of presynaptic step depolarizations (as in Fig. 3C) was followed $500 \mathrm{msec}$ later by one test depolarization to assess the degree of recovery from synaptic depression. EPSCs recorded from the postsynaptic MNTB neuron during the conditioning train showed substantial synaptic depression (Fig. 4B), which recovered within $500 \mathrm{msec}$. The $I_{\mathrm{Ca}}$ elicited by the test depolarization was reduced to $90.4 \pm 1.6 \%(n=3 ; p=0.03)$ compared with the first $I_{\mathrm{Ca}}$ of the conditioning train (Fig. $4 C, D$ ) because of the build-up of inactivation of the presynaptic calcium channels (Forsythe et al., 1998). However, the magnitude of this reduction was unchanged by mitochondrial depolarization or inhibiting mitochondrial calcium sequestration with $\operatorname{Ru360}(n=3 ; p=0.17$ and 0.27 , respectively) (Fig. $4 D$ ), indicating that the action of these drugs on neurotransmitter release (see below) was not mediated by a change in $I_{\mathrm{Ca}}$. The size of the test EPSC was measured under control conditions and after mitochondrial inhibitors in the same terminals. A difference in the test EPSC amplitude should indicate whether mitochondrial calcium sequestration modulates neurotransmitter release. Under control conditions, the test EPSC recovered to $81 \pm 4 \%(n=3)$ of the initial train amplitude after $500 \mathrm{msec}$. After mitochondrial depolarization (reducing $\mathrm{Ca}^{2+}$ sequestration but maintaining presynaptic [ATP] as for Fig. 3) the rate of recovery of the EPSC train was slowed, such that the magnitude of the test EPSC recovered to 
A

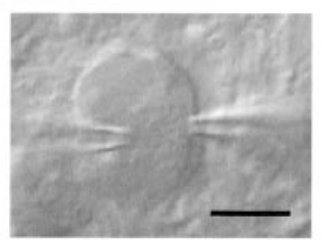

B

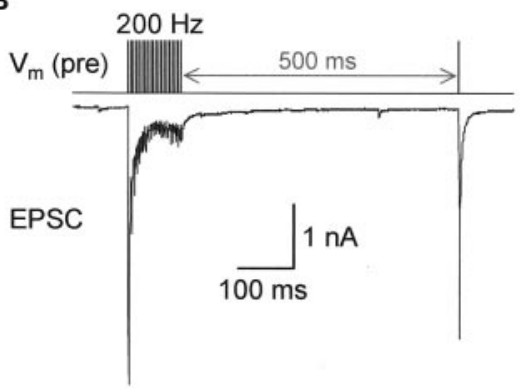

$\mathbf{F}$

E

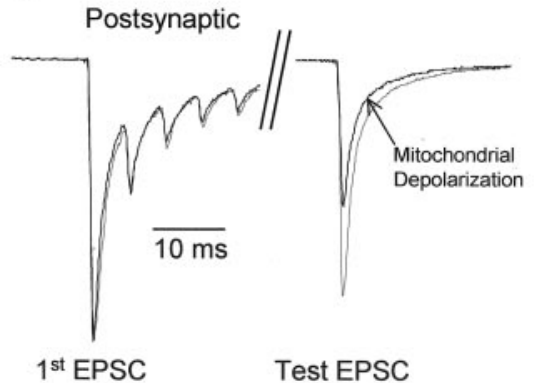

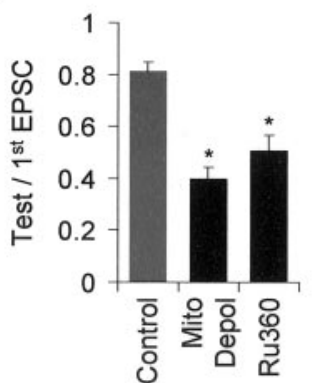

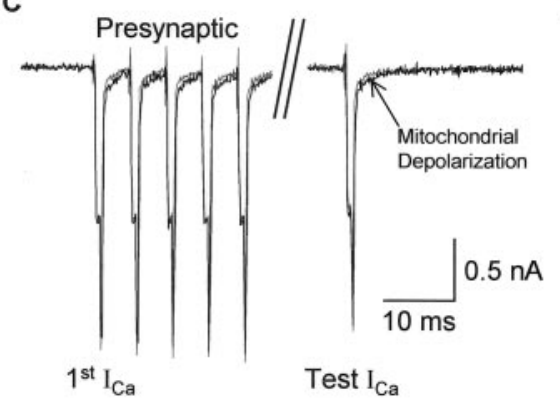

G

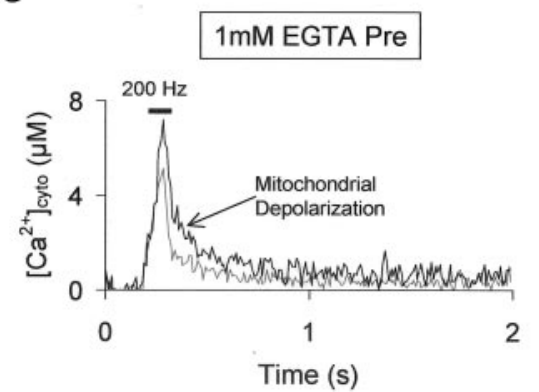

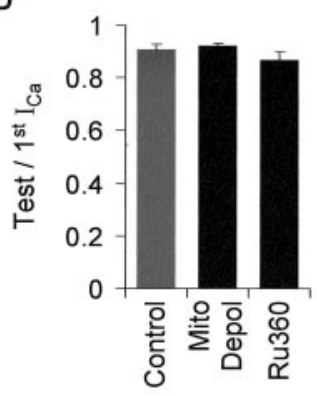

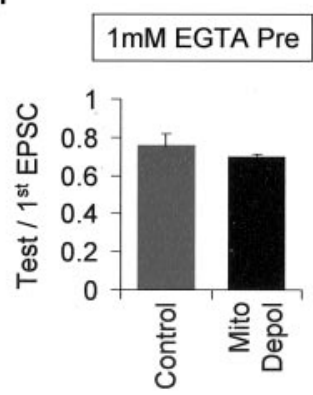

Figure 4. Presynaptic mitochondrial calcium sequestration influences synaptic transmission. $A$, The postsynaptic MNTB neuron and presynaptic calyx were simultaneously voltage clamped. Scale bar, $10 \mu \mathrm{m}$. B. Trains of stimuli (as in Fig. $3 C$ ) produced a markedly depressing EPSC train. At 500 msec after the end of the train, the EPSC had recovered to $81 \%$ of control amplitude. $C$, $D$, Presynaptic calcium currents recorded in response to the train were unaffected by mitochondrial depolarization. $E$, Postsynaptic currents normalized to the magnitude of the first EPSC. The absolute magnitude of the EPSC was $-4.6 \pm 0.4 \mathrm{nA}$ before mitochondrial depolarization and $-4.3 \pm 0.4 \mathrm{nA}$ after. This $6 \pm 2 \%$ reduction was a time-dependent run-down and was not statistically significant $(n=3 ; p=0.07)$. Mitochondrial depolarization induced by rotenone and FCCP in the presence of oligomycin had no effect on the initial train amplitude and time course, but it significantly reduced the relative magnitude of the test EPSC. $F$, Identical results were observed after mitochondrial depolarization or by blocking the calcium uniporter with intracellular Ru360 $(1 \mu \mathrm{M})$. $G$, Inclusion of 1 mM EGTA in the presynaptic patch pipette accelerated the decay and reduced the effect of mitochondrial depolarization on the presynaptic calcium transient. $H$, Presynaptic EGTA at 1 mm abolished the effects of mitochondrial depolarization on the rate of recovery from synaptic depression. Asterisks indicate statistical significance $(p<0.05)$.

only $40 \pm 5 \%$ of control after $500 \mathrm{msec}(n=3 ; p<0.01)$ (Fig. $4 E, F)$. Similarly, Ru360 slowed the recovery rate of the EPSC train, resulting in the magnitude of the test EPSC recovering to $51 \pm 6 \%$ of the initial amplitude $(n=3 ; p=0.01)$. To demonstrate that the synaptic depression induced by mitochondrial depolarization is mediated by changes in the dynamics of the presynaptic calcium transient, the concentration of the calcium buffer (EGTA) in the presynaptic terminal was increased from $200 \mu \mathrm{M}$ to $1 \mathrm{~mm}$ (Borst and Sakmann, 1996; Dittman and Regehr, 1998; Wang and Kaczmarek, 1998; Wu and Borst, 1999). With this additional presynaptic calcium buffering the $\tau_{\text {fast }}$ of the $\left[\mathrm{Ca}^{2+}\right]_{\text {cyto }}$ transient was $35 \pm 3 \mathrm{msec}$ under control conditions and only slowed to $73 \pm 10 \mathrm{msec}$ during mitochondrial depolarization (compare Figs. 3C, 4G). The effects of mitochondrial depolarization on the rate of recovery of the EPSC from synaptic depression were completely abolished by the additional EGTA $(p=0.38 ; n=3)$ (Fig. $4 H)$, strongly implicating $\left[\mathrm{Ca}^{2+}\right]_{\text {cyto }}$ in mediating this effect. Thus, our present data using two independent methods of blocking mitochondrial calcium sequestration, indicate that mitochondria can modulate synaptic transmission by accelerating the recovery from short-term presynaptic depression.

\section{DISCUSSION}

We have described a technique for imaging both cytoplasmic and mitochondrial calcium in the same presynaptic terminal at a mammalian central synapse. Using this method we showed that mitochondria rapidly sequester substantial quantities of cytoplasmic calcium, significantly buffering $\left[\mathrm{Ca}^{2+}\right]_{\text {cyto }}$ and influencing neurotransmitter release on millisecond time scales. The selective loading of fluorescent dyes relies on the ability to include the AM ester of the rhod dye in the patch pipette, resulting in accumulation of de-esterified dye in the mitochondria. Loading is thus limited to the mitochondria within the patch-clamped cell, and cytoplasmic fluorescence is removed by dialysis into the pipette. Loading occurs rapidly (within a few minutes), and extensive periods of washing to remove cytoplasmic rhod are not required. Manganese quenching is also not required, which enables simultaneous use of a cytoplasmic dye and avoids problems with manganese block of calcium channels and neurotransmission (Hagiwara and Nakajima, 1966; Llinas et al., 1981; Augustine et al., 1985).

We are confident that the fluorescence labeling seen with the rhod dyes is mitochondrial for three reasons: First, contrasting localization of rhod and fura dyes (Fig. 2B,C). Second, different time course of the mitochondrial calcium signal compared with $\left[\mathrm{Ca}^{2+}\right]_{\text {cyto }}$ (compare Figs. $1 D, 2 E$ ). And third, the sensitivity of the fluorescence signal to mitochondrial depolarization, $\mathrm{TPP}^{+}$ and RU360. The lack of effect of thapsigargin on the rhod fluorescence signal demonstrates that the signal does not originate from the endoplasmic reticulum and implies that mitochondria are the predominant presynaptic calcium store.

\section{Simultaneous mitochondrial and cytoplasmic imaging}

The long excitation wavelength of rhod-2 and rhod-FF (500-600 $\mathrm{nm})$ enables simultaneous measurement of $\left[\mathrm{Ca}^{2+}\right]_{\text {mito }}$ and $\left[\mathrm{Ca}^{2+}\right]_{\text {cyto }}$ by combined loading with shorter wavelength dyes 
such as fluo-3 (Simpson and Russell, 1998; Boitier et al., 1999; Gonzalez et al., 2000; Trollinger et al., 2000; Collins et al., 2001; Rakhit et al., 2001), fura-2 (Simpson and Russell, 1996; Drummond and Tuft, 1999; Drummond et al., 2000), calcium green (Babcock et al., 1997; Peng and Greenamyre, 1998), and Oregon green BAPTA 5N (David et al., 1998). In our studies we combined rhod AM loading with fura-FF salt in the patch pipette. The salt of the fura dye is not membrane-permeable and will remain in the cytoplasm, ensuring that fura and rhod report $\left[\mathrm{Ca}^{2+}\right]$ from separate subcellular compartments (Fig. 2B,C). Fura-FF has a relatively low affinity for calcium (Bollmann et al., 2000; Schneggenburger and Neher, 2000) and is ideal for imaging the large presynaptic rises in $\left[\mathrm{Ca}^{2+}\right]_{\text {cyto }}$ with minimal spectral overlap with rhod dyes.

\section{The magnitude of $\left[\mathrm{Ca}^{2+}\right]_{\text {mito }}$ rises}

A brief stimulus train $(100 \mathrm{msec}$ at $200 \mathrm{~Hz})$ resulted in a rapid rise in $\left[\mathrm{Ca}^{2+}\right]_{\text {mito }}$ that saturated rhod-2 (Fig. 2D). Rhod-FF is a new low-affinity indicator that overcomes this saturation problem and enables the large rises in $\left[\mathrm{Ca}^{2+}\right]_{\text {mito }}$ to be resolved (Fig. 2E). During stimulation, a minimum $\left[\mathrm{Ca}^{2+}\right]_{\text {mito }}$ rise of $\sim 5 \mu \mathrm{M}$ was calculated based on the resting calcium level and saturation of rhod-2. This rise is consistent with studies using mitochondrially targeted aequorin proteins that have shown $\left[\mathrm{Ca}^{2+}\right]_{\text {mito }}$ rises of 5-20 $\mu \mathrm{M}$ in transfected cell lines on agonist application (Rizzuto et al., 1992; Rutter et al., 1996) and $\sim 300 \mu \mathrm{M}$ in chronically depolarized bovine chromaffin cells (Montero et al., 2000). Our findings contrast with studies at the lizard neuromuscular junction where $\left[\mathrm{Ca}^{2+}\right]_{\text {mito }}$ rises after stimulation are delayed and do not saturate rhod-2 (David et al., 1998). It seems likely that the proximal location of presynaptic mitochondria to release sites (Rowland et al., 2000) has a major impact on the rate and functional significance of mitochondrial calcium sequestration at the mammalian synapse. The distal location of mitochondria at goldfish bipolar cell synapses may explain their minor contribution to sequestration at that site (Zenisek and Matthews, 2000).

\section{Prevention of ATP depletion}

Blocking mitochondrial calcium sequestration had a significant effect on the release of neurotransmitter after a train of stimulation (Fig. 4E). There are four reasons why this effect was not mediated by depletion of ATP after mitochondrial poisoning: first, ATP was continually applied via the patch pipette. Second, oligomycin alone had no effect on EPSC amplitude. Third, TPP and RU360 prevented mitochondrial calcium uptake without depolarizing $\Delta \psi_{\mathrm{m}}$ and depleting ATP (Aiuchi et al., 1985; Matlib et al., 1998). And forth, the effects of mitochondrial inhibitors were reversed by the inclusion of $1 \mathrm{~mm}$ EGTA in the intracellular solution, indicating mediation by an intracellular calcium buffering mechanism.

\section{Recovery from synaptic depression}

Previous reports have shown that increased presynaptic calcium buffering slows the recovery from synaptic depression (Dittman and Regehr, 1998; Stevens and Wesseling, 1998; Wang and Kaczmarek, 1998). This is contrary to our results where presynaptic terminals with lower calcium buffering (caused by removal of the mitochondrial calcium sequestration) show slower recovery from synaptic depression. The residual calcium hypothesis (Katz, 1969) suggests that neurotransmitter release would be enhanced rather that depressed by this additional free calcium. There is good evidence that $\left[\mathrm{Ca}^{2+}\right]_{\text {cyto }}$ plays multiple roles in regulating the vesicle cycle. For instance, elevated $\left[\mathrm{Ca}^{2+}\right]_{\text {cyto }}$ can inhibit endocytosis at the goldfish bipolar cell synapse (von Gersdorff and Matthews, 1994) and interact with regulators of dynamin to inhibit endocytosis in mammalian nerve terminals (Cousin and Robinson, 2000). Furthermore, the Rab GTPases are activated by $\mathrm{Ca}^{2+}$-calmodulin, causing inhibition of vesicle cycling (Coppola et al., 1999), although $\mathrm{Ca}^{2+}$-calmodulin has also been shown to promote refilling of the rapidly releasing pool of vesicles after high-frequency stimulation (Sakaba and Neher, 2001). The overall effect of $\left[\mathrm{Ca}^{2+}\right]_{\text {cyto }}$ on transmitter release will therefore depend on the balance between these processes. In addition, the subcellular location of the $\left[\mathrm{Ca}^{2+}\right]_{\text {cyto }}$ rise is critical in determining its action. The exogenous mobile calcium buffers applied in previous experiments (Dittman and Regehr, 1998; Stevens and Wesseling, 1998; Wang and Kaczmarek, 1998) will freely diff use throughout the cytoplasm and influence $\left[\mathrm{Ca}^{2+}\right]_{\text {cyto }}$ close to the site of calcium influx. Because mitochondria are located 100-500 $\mathrm{nm}$ from the release sites (Lysakowski et al., 1999; Rowland et al., 2000 ) and constitute $22 \%$ of the presynaptic volume (data from the endbulb of Held; M. Nicol and B. Walmsley, personal communication) (Nichol and Walmsley, 2002), they are ideally situated to sequester calcium from the bulk cytoplasm. Hence, they differentially influence the vesicle cycle compared with mobile exogenous buffers, and they could provide a crucial link between presynaptic metabolic activity and neurotransmitter release.

\section{Functional relevance}

Reduced calcium sequestration by mitochondria is associated with aging (Leslie et al., 1985) and neurodegenerative conditions such as amyotrophic lateral sclerosis, Huntington's disease, and Alzheimer's disease (Beal, 2000). In addition, symptoms similar to Parkinson's disease can result from inhibition of mitochondrial respiration by rotenone (Betarbet et al., 2000). Hence, the influence of mitochondrial calcium sequestration on synaptic transmission has important implications for cognitive function. Although there are some studies suggesting that calcium release from endoplasmic reticulum can influence synaptic transmission at other synapses (Llano et al., 2000; Emptage et al., 2001), our data suggest that mitochondria are the major intracellular calcium store in this mammalian glutamatergic terminal. Acting in concert with mobile calcium-binding proteins (Lee et al., 2000) and plasma membrane calcium pumps (Garcia and Strehler, 1999), mitochondria will shape cytoplasmic calcium transients and serve as an intermediary in calcium export. Our observations demonstrate that mitochondria also function in short-term presynaptic modulation on a millisecond time scale and with much lower presynaptic calcium loads than previously thought.

\section{REFERENCES}

Aiuchi T, Matsunaga M, Nakaya K, Nakamura Y (1985) Effects of probes of membrane potential on metabolism in synaptosomes. Biochim Biophys Acta 843:20-24.

Augustine GJ, Charlton MP, Smith SJ (1985) Calcium entry into voltage-clamped presynaptic terminals of squid. J Physiol (Lond) 367:143-162.

Babcock DF, Herrington J, Goodwin PC, Park YB, Hille B (1997) Mitochondrial participation in the intracellular $\mathrm{Ca}^{2+}$ network. J Cell Biol 136:833-844.

Beal MF (2000) Energetics in the pathogenesis of neurodegenerative diseases. Trends Neurosci 23:298-304.

Betarbet R, Sherer TB, MacKenzie G, Garcia-Osuna M, Panov AV, Greenamyre JT (2000) Chronic systemic pesticide exposure reproduces features of Parkinson's disease. Nat Neurosci 3:1301-1306.

Boitier E, Rea R, Duchen MR (1999) Mitochondria exert a negative feedback on the propagation of intracellular $\mathrm{Ca}^{2+}$ waves in rat cortical astrocytes. J Cell Biol 145:795-808.

Bollmann JH, Sakmann B, Borst JG (2000) Calcium sensitivity of glutamate release in a calyx-type terminal. Science 289:953-957. 
Borst JG, Sakmann B (1996) Calcium influx and transmitter release in a fast CNS synapse. Nature 383:431-434.

Borst JG, Sakmann B (1998) Calcium current during a single action potential in a large presynaptic terminal of the rat brainstem. J Physiol (Lond) 506:143-157.

Borst JG, Helmchen F, Sakmann B (1995) Pre- and postsynaptic wholecell recordings in the medial nucleus of the trapezoid body of the rat. J Physiol (Lond) 489:825-840.

Brownell WE (1975) Organization of the cat trapezoid body and the discharge characteristics of its fibers. Brain Res 94:413-433.

Cao YJ, Peng YY (1999) Caffeine and carbonyl cyanide m-chlorophenylhydrazone increased evoked and spontaneous release of luteinizing hormone-releasing hormone from intact presynaptic terminals. Neuroscience 92:1511-1521.

Collins TJ, Lipp P, Berridge MJ, Bootman MD (2001) Mitochondrial $\mathrm{Ca}^{2+}$ uptake depends on the spatial and temporal profile of cytosolic $\mathrm{Ca}^{2+}$ signals. J Biol Chem 276:26411-26420.

Coppola T, Perret-Menoud V, Luthi S, Farnsworth CC, Glomset JA, Regazzi R (1999) Disruption of Rab3-calmodulin interaction, but not other effector interactions, prevents Rab3 inhibition of exocytosis. EMBO J 18:5885-5891.

Cousin MA, Robinson PJ (2000) $\mathrm{Ca}^{2+}$ influx inhibits dynamin and arrests synaptic vesicle endocytosis at the active zone. J Neurosci 20:949-957.

David G (1999) Mitochondrial clearance of cytosolic $\mathrm{Ca}^{2+}$ in stimulated lizard motor nerve terminals proceeds without progressive elevation of mitochondrial matrix $\left[\mathrm{Ca}^{2+}\right]$. J Neurosci 19:7495-7506.

David G, Barrett EF (2000) Stimulation-evoked increases in cytosolic $\left[\mathrm{Ca}^{2+}\right]$ in mouse motor nerve terminals are limited by mitochondrial uptake and are temperature dependent. J Neurosci 20:7290-7296.

David G, Barrett JN, Barrett EF (1998) Evidence that mitochondria buffer physiological $\mathrm{Ca}^{2+}$ loads in lizard motor nerve terminals. J Physiol (Lond) 509:59-65.

Dittman JS, Regehr WG (1998) Calcium dependence and recovery kinetics of presynaptic depression at the climbing fiber to Purkinje cell synapse. J Neurosci 18:6147-6162.

Drummond RM, Tuft RA (1999) Release of $\mathrm{Ca}^{2+}$ from the sarcoplasmic reticulum increases mitochondrial $\left[\mathrm{Ca}^{2+}\right]$ in rat pulmonary artery smooth muscle cells. J Physiol (Lond) 516:139-147.

Drummond RM, Mix TC, Tuft RA, Walsh Jr JV, Fay FS (2000) Mitochondrial $\mathrm{Ca}^{2+}$ homeostasis during $\mathrm{Ca}^{2+}$ influx and $\mathrm{Ca}^{2+}$ release in gastric myocytes from Bufo marinus. J Physiol (Lond) 522:375-390.

Duchen MR (1999) Contributions of mitochondria to animal physiology: from homeostatic sensor to calcium signalling and cell death. J Physiol (Lond) 516:1-17.

Emptage NJ, Reid CA, Fine A (2001) Calcium stores in hippocampal synaptic boutons mediate short-term plasticity, store-operated $\mathrm{Ca}^{2+}$ entry, and spontaneous transmitter release. Neuron 29:197-208.

Forsythe ID (1994) Direct patch recording from identified presynaptic terminals mediating glutamatergic EPSCs in the rat CNS, in vitro. J Physiol (Lond) 479:381-387.

Forsythe ID, Tsujimoto T, Barnes-Davies M, Cuttle MF, Takahashi T (1998) Inactivation of presynaptic calcium current contributes to synaptic depression at a fast central synapse. Neuron 20:797-807.

Garcia ML, Strehler EE (1999) Plasma membrane calcium ATPases as critical regulators of calcium homeostasis during neuronal cell function. Front Biosci 4:D869-D882.

Giovannucci DR, Hlubek MD, Stuenkel EL (1999) Mitochondria regulate the $\mathrm{Ca}^{2+}$-exocytosis relationship of bovine adrenal chromaffin cells. J Neurosci 19:9261-9270.

Gonzalez A, Schulz I, Schmid A (2000) Agonist-evoked mitochondrial $\mathrm{Ca}^{2+}$ signals in mouse pancreatic acinar cells. $\mathrm{J}$ Biol Chem 275:38680-38686.

Gunter KK, Gunter TE (1994) Transport of calcium by mitochondria. J Bioenerg Biomembr 26:471-485.

Gunter TE, Pfeiffer DR (1990) Mechanisms by which mitochondria transport calcium. Am J Physiol 258:C755-C786.

Hagiwara S, Nakajima S (1966) Differences in $\mathrm{Na}^{+}$and $\mathrm{Ca}^{2+}$ spikes as examined by application of tetrodotoxin, procaine, and manganese ions. J Gen Physiol 49:793-806.

Helmchen F, Borst JG, Sakmann B (1997) Calcium dynamics associated with a single action potential in a CNS presynaptic terminal. Biophys J 72:1458-1471.

Herrington J, Park YB, Babcock DF, Hille B (1996) Dominant role of mitochondria in clearance of large $\mathrm{Ca}^{2+}$ loads from rat adrenal chromaffin cells. Neuron 16:219-228.

Iwasaki S, Takahashi T (1998) Developmental changes in calcium channel types mediating synaptic transmission in rat auditory brainstem. J Physiol (Lond) 509:419-423.

Jaffe DB, Johnston D, Lasser-Ross N, Lisman JE, Miyakawa H, Ross WN (1992) The spread of $\mathrm{Na}^{+}$spikes determines the pattern of dendritic $\mathrm{Ca}^{2+}$ entry into hippocampal neurons. Nature 357:244-246.

Kaftan EJ, Xu T, Abercrombie RF, Hille B (2000) Mitochondria shape hormonally induced cytoplasmic calcium oscillations and modulate exocytosis. J Biol Chem 275:25465-25470.
Katz B (1969) The release of neural transmitter substances. Springfield, IL: Thomas.

Kobayashi K, Tachibana M (1995) $\mathrm{Ca}^{2+}$ regulation in the presynaptic terminals of goldfish retinal bipolar cells. J Physiol (Lond) 483:79-94

Lee SH, Schwaller B, Neher E (2000) Kinetics of $\mathrm{Ca}^{2+}$ binding to parvalbumin in bovine chromaffin cells: implications for $\left[\mathrm{Ca}^{2+}\right]$ transients of neuronal dendrites. J Physiol (Lond) 525:419-432.

Leslie SW, Chandler LJ, Barr EM, Farrar RP (1985) Reduced calcium uptake by rat brain mitochondria and synaptosomes in response to aging. Brain Res 329:177-183.

Llano I, Gonzalez J, Caputo C, Lai FA, Blayney LM, Tan YP, Marty A (2000) Presynaptic calcium stores underlie large-amplitude miniature IPSCs and spontaneous calcium transients. Nat Neurosci 3:1256-1265.

Llinas R, Steinberg IZ, Walton K (1981) Presynaptic calcium currents in squid giant synapse. Biophys J 33:289-321.

Lysakowski A, Figueras H, Price SD, Peng YY (1999) Dense-cored vesicles, smooth endoplasmic reticulum, and mitochondria are closely associated with non-specialized parts of plasma membrane of nerve terminals: implications for exocytosis and calcium buffering by intraterminal organelles. J Comp Neurol 403:378-390.

Matlib MA, Zhou Z, Knight S, Ahmed S, Choi KM, Krause-Bauer J, Phillips R, Altschuld R, Katsube Y, Sperelakis N, Bers DM (1998) Oxygen-bridged dinuclear ruthenium amine complex specifically inhibits $\mathrm{Ca}^{2+}$ uptake into mitochondria in vitro and in situ in single cardiac myocytes. J Biol Chem 273:10223-10231.

Minta A, Kao JP, Tsien RY (1989) Fluorescent indicators for cytosolic calcium based on rhodamine and fluorescein chromophores. J Biol Chem 264:8171-8178.

Mironov SL, Richter DW (2001) Oscillations and hypoxic changes of mitochondrial variables in neurons of the brainstem respiratory centre of mice. J Physiol (Lond) 533:227-236.

Montero M, Alonso MT, Carnicero E, Cuchillo-Ibanez I, Albillos A, Garcia AG, Garcia-Sancho J, Alvarez J (2000) Chromaffin-cell stimulation triggers fast millimolar mitochondrial $\mathrm{Ca}^{2+}$ transients that modulate secretion. Nat Cell Biol 2:57-61.

Neher E, Sakaba T (2001) Combining deconvolution and noise analysis for the estimation of transmitter release rates at the calyx of Held. J Neurosci 21:444-461.

Nichol MJ, Walmsley B (2002) Ultrastructural basis of synaptic transmission between endbulbs of Held and bushy cells in the rat cochlear nucleus. J Physiol (Lond) 539:713-723.

Nicholls DG, Budd SL (2000) Mitochondria and neuronal survival. Physiol Rev 80:315-360.

Park YB, Herrington J, Babcock DF, Hille B (1996) $\mathrm{Ca}^{2+}$ clearance mechanisms in isolated rat adrenal chromaffin cells. J Physiol (Lond) 492:329-346.

Peng TI, Greenamyre JT (1998) Privileged access to mitochondria of calcium influx through $N$-methyl-D-aspartate receptors. Mol Pharmacol 53:974-980.

Peng YY (1998) Effects of mitochondrion on calcium transients at intact presynaptic terminals depend on frequency of nerve firing. J Neurophysiol 80:186-195.

Rakhit RD, Mojet MH, Marber MS, Duchen MR (2001) Mitochondria as targets for nitric oxide-induced protection during simulated ischemia and reoxygenation in isolated neonatal cardiomyocytes. Circulation 103:2617-2623.

Rizzuto R, Simpson AW, Brini M, Pozzan T (1992) Rapid changes of mitochondrial $\mathrm{Ca}^{2+}$ revealed by specifically targeted recombinant aequorin. Nature 358:325-327.

Rohacs T, Nagy G, Spat A (1997) Cytoplasmic $\mathrm{Ca}^{2+}$ signalling and reduction of mitochondrial pyridine nucleotides in adrenal glomerulosa cells in response to $\mathrm{K}^{+}$, angiotensin II and vasopressin. Biochem $\mathrm{J}$ 322:785-792

Rowland KC, Irby NK, Spirou GA (2000) Specialized synapseassociated structures within the calyx of Held. J Neurosci 20:9135-9144

Rutter GA, Burnett P, Rizzuto R, Brini M, Murgia M, Pozzan T, Tavare JM, Denton RM (1996) Subcellular imaging of intramitochondrial $\mathrm{Ca}^{2+}$ with recombinant targeted aequorin: significance for the regulation of pyruvate dehydrogenase activity. Proc Natl Acad Sci USA 93:5489-5494.

Sakaba T, Neher E (2001) Calmodulin mediates rapid recruitment of fast-releasing synaptic vesicles at a calyx-type synapse. Neuron 32:1119-1131.

Schneggenburger R, Neher E (2000) Intracellular calcium dependence of transmitter release rates at a fast central synapse. Nature 406:889-893

Simpson PB, Russell JT (1996) Mitochondria support inositol 1, 4, 5-trisphosphate-mediated $\mathrm{Ca}^{2+}$ waves in cultured oligodendrocytes. J Biol Chem 271:33493-33501.

Simpson PB, Russell JT (1998) Mitochondrial $\mathrm{Ca}^{2+}$ uptake and release influence metabotropic and ionotropic cytosolic $\mathrm{Ca}^{2+}$ responses in rat oligodendrocyte progenitors. J Physiol (Lond) 508:413-426.

Sorimachi M, Nishimura S, Yamagami K (1999) Sequestration of depolarization-induced $\mathrm{Ca}^{2+}$ loads by mitochondria and $\mathrm{Ca}^{2+}$ efflux 
via mitochondrial $\mathrm{Na}^{+} / \mathrm{Ca}^{2+}$ exchanger in bovine adrenal chromaffin cells. Jpn J Physiol 49:35-46.

Stevens CF, Wesseling JF (1998) Activity-dependent modulation of the rate at which synaptic vesicles become available to undergo exocytosis. Neuron 21:415-424.

Szabadkai G, Pitter JG, Spat A (2001) Cytoplasmic $\mathrm{Ca}^{2+}$ at low submicromolar concentration stimulates mitochondrial metabolism in rat luteal cells. Pflügers Arch 441:678-685.

Takahashi T, Forsythe ID, Tsujimoto T, Barnes-Davies M, Onodera K (1996) Presynaptic calcium current modulation by a metabotropic glutamate receptor. Science 274:594-597.

Tang Y, Zucker RS (1997) Mitochondrial involvement in post-tetanic potentiation of synaptic transmission. Neuron 18:483-491.

Trollinger DR, Cascio WE, Lemasters JJ (2000) Mitochondrial calcium transients in adult rabbit cardiac myocytes: inhibition by ruthenium red and artifacts caused by lysosomal loading of $\mathrm{Ca}^{2+}$-indicating fluorophores. Biophys J 79:39-50. von Gersdorff H, Matthews G (1994) Inhibition of endocytosis by elevated internal calcium in a synaptic terminal. Nature 370:652-655.

von Gersdorff H, Schneggenburger R, Weis S, Neher E (1997) Presynaptic depression at a calyx synapse: the small contribution of metabotropic glutamate receptors. J Neurosci 17:8137-8146.

Wang LY, Kaczmarek LK (1998) High-frequency firing helps replenish the readily releasable pool of synaptic vesicles. Nature 394:384-388.

Wu LG, Borst JG (1999) The reduced release probability of releasable vesicles during recovery from short-term synaptic depression. Neuron 23:821-832.

Xu T, Naraghi M, Kang H, Neher E (1997) Kinetic studies of $\mathrm{Ca}^{2+}$ binding and $\mathrm{Ca}^{2+}$ clearance in the cytosol of adrenal chromaffin cells. Biophys J 73:532-545.

Zenisek D, Matthews G (2000) The role of mitochondria in presynaptic calcium handling at a ribbon synapse. Neuron 25:229-237.

Zhou Z, Matlib MA, Bers DM (1998) Cytosolic and mitochondrial $\mathrm{Ca}^{2+}$ signals in patch clamped mammalian ventricular myocytes. J Physiol (Lond) 507:379-403. 